\section{Niveis de fósforo via adubação em três variedades de sorgo forrageiro: Características agronômicas}

\author{
Phosphorus fertilization in three cultivars of forage sorghum: \\ crop factors
}

Farnésio de Sousa Cavalcante ${ }^{1 *}$, Ivandro de França da Silva², Alberício Pereira de Andrade², José Nildo Tabosa', Sérvulo Mercier Siqueira e Silva ${ }^{3}$
'Instituto Agronômico de Pernambuco (IPA), Av. General San Martin, 1371, CEP 50761-000, Bongi,

Recife, PE, Brasil

Universidade Federal da Paraíba (UFPB), João Pessoa, PB, Brasil 'Estação Experimental de Serra Talhada, Instituto Agronômico de Pernambuco (IPA). Serra Talhada PE, Brasil

*autor correspondente 凶 farnesio.cavalcante@ipa.br
RESUMO: O fósforo, além de sua adsorção, é deficiente nos solos da região semiárida brasileira, o que torna a adubação, em níveis adequados, uma prática necessária para a manutenção e/ou elevação da produção agrícola, especialmente das forragens, aproveitando ao máximo a água das chuvas, no âmbito da conservação com o uso adequado do solo e a convivência sob altas temperaturas nessa região. Objetivando avaliar os fatores de produção de três variedades de sorgo forrageiro (IPA 4-6-7/42, IPA 2-3-1 e IPA SF-25), em sistema de sequeiro, mediante aplicação de fósforo nas doses: 0, 40, 80, 120 e $160 \mathrm{~kg} \mathrm{ha}^{-1}$ de $\mathrm{P}_{2} \mathrm{O}_{5}$, sob a forma de superfosfato triplo, foi realizado um experimento em Luvissolo Crômico no sertão de Pernambuco. O delineamento estatístico foi o de blocos casualizados em esquema fatorial $(3 \times 5)$, com quatro repetições. Os efeitos das doses de $P$ foram independentes dos efeitos das culturas. A variedade IPA 4-6-7/42 apresentou melhor desempenho em relação às outras duas variedades em todos os parâmetros analisados.

PALAVRAS-CHAVE: Agricultura de sequeiro, forragicultura, solos, sorgo.
ABSTRACT: Phosphorus, besides its adsorption, is deficient in the soils of the Brazilian semiarid region, which makes the use of fertilizer at appropriate levels a necessary practice to maintain and/or increase agricultural production, particularly of forages, taking full advantage of rainwater regarding conservation through the appropriate use of land under the high temperatures in this region. An experiment was conducted in Chromic Luvisol in the state of Pernambuco in order to evaluate the production factors of three cultivars of sorghum (IPA 4-6-7/42, IPA 2-3-1 and IPA SF-25), in rainfed systems, through the application of phosphorus at rates of 0, 40,80, 120 and $160 \mathrm{~kg} \mathrm{ha}^{-1} \mathrm{P}_{2} \mathrm{O}_{5}$ in the form of triple superphosphate. We used statistical design of randomized blocks in $(3 \times 5)$ factorial with four replications. The effects of $P$ rates were independent of the crops. The cultivar IPA 4-6-7/42 showed better performance than the other two cultivars studied in all parameters.

KEYWORDS: Rainfed agriculture, forage, soils, sorghum.

\title{
Introdução
}

O sorgo forrageiro possui diversas vantagens em relação a outras gramíneas, tais como: precocidade, maior número de colheitas, conforme o regime hídrico, contribui com $10 \%$ a $15 \%$ da área total cultivada para silagem no Brasil, destacando-se, de modo geral, por apresentar produtividade de matéria seca (t MS/ha/ano) mais elevada que a do milho, principalmente em locais onde é frequente a ocorrência de longas estiagens (AVELINO et al., 2011).

A prática da adubação possibilita a elevação da produtividade das culturas, refletindo no custo final de produção. O 
fornecimento de adubação fosfatada faz-se necessário, uma vez que as limitações na disponibilidade de fósforo no início do ciclo vegetativo podem resultar em restrições no desenvolvimento, das quais a planta não se recupera posteriormente (GRANT et al., 2001), o que pode comprometer o crescimento e o aporte de biomassa, produto principal dessa forrageira.

Outro fator de extrema importância no cultivo do sorgo para a produção de forragem é a escolha de variedades mais bem adaptadas ao clima e solo conforme sua finalidade para a utilização em silagem, corte, fenação, pastejo direto e produção de grãos (THOMAZINI; PACHECO; CAVALCANTE, 2004).

O Instituto Agronômico de Pernambuco (IPA) vem trabalhando com algumas variedades de sorgo forrageiro, entre as quais se têm destacado a IPA 467-4-2, IPA 02-03-01 e a IPA SF 25, sendo recomendadas para a região semiárida de Pernambuco e demais unidades da Federação. Além disso, as variedades locais, que foram desenvolvidas para o semiárido, apresentam elevado potencial de produção de forragem, uma configurada adaptabilidade ao ambiente (LIMA, 1998).

Atualmente, as novas variedades de sorgo forrageiro disponíveis no mercado têm alta produtividade, resistência às doenças, boa estabilidade de produção, diferenciadas entre plantas de ciclos médio e curto, o que diminui os riscos de perda para o produtor (OLIVEIRA et al., 2005).

O objetivo deste trabalho foi o de avaliar as características agronômicas, produção e rendimento de forragem de três variedades de sorgo forrageiro, submetido a diferentes níveis de fósforo, utilizando-se como fonte o superfosfato triplo no semiárido pernambucano.

\section{Material e Métodos}

$\mathrm{O}$ experimento foi conduzido durante os meses de abril a agosto de 2007, na Estação Experimental Lauro Ramos Bezerra, pertencente ao Instituto Agronômico de Pernambuco (IPA), município de Serra Talhada, Sertão de Pernambuco - Brasil. As coordenadas geográficas locais de referência foram: Latitude $07^{\circ} 56^{\prime}$ 58,9' S e Longitude $38^{\circ} 17^{\prime}$ '41" W.GR e $506 \mathrm{~m}$ de altitude. O clima da região, de acordo com a classificação de Thornthwait, é do tipo semiárido megatérmico (DdA'a') com duas estações climáticas: uma chuvosa (novembro-fevereiro) e outra seca (março-outubro) (OMETTO, 1981). A precipitação anual média é de $650 \mathrm{~mm}$, a umidade relativa do ar é de $67 \%$ e a temperatura varia de 27 a $36{ }^{\circ} \mathrm{C}$, sendo a média anual de $34{ }^{\circ} \mathrm{C}$.

$\mathrm{O}$ solo da área do experimento foi classificado em Luvissolo Crômico, fase caatinga hiperxerófila (EMBRAPA, 1999), com textura leve na superfície, conteúdo de argila aumentando na profundidade, e apresentava as seguintes características na camada de 0 a $30 \mathrm{~cm}$ : $\mathrm{pH}\left(\mathrm{em} \mathrm{H}_{2} \mathrm{O}\right)=6,48$; Al trocável $\left(\mathrm{cmol}_{\mathrm{c}}\right.$ $\left.\mathrm{dm}^{-3}\right)=0,0 ; \mathrm{Ca}\left(\mathrm{cmol}_{\mathrm{c}} \mathrm{dm}^{-3}\right)=2,66 ; \mathrm{Mg}\left(\mathrm{cmol}_{\mathrm{c}} \mathrm{dm}^{-3}\right)=1,67$ P-Mehlich $1\left(\mathrm{mg} \mathrm{dm}^{-3}\right)=42,31 ; \mathrm{K}\left(\mathrm{mg} \mathrm{dm}^{-3}\right)=62,0$; Matéria orgânica $=5,2\left(\mathrm{~g} \mathrm{dm}^{-3}\right) ; \mathrm{V}(\%)=79,13 ; \mathrm{m}(\%)=0,0$; Soma de bases $=4,99\left(\mathrm{cmol}_{\mathrm{c}} \mathrm{dm}^{-3}\right) ;$ CTC $=6,32\left(\mathrm{cmol}_{\mathrm{c}} \mathrm{dm}^{-3}\right)$; Argila $=95,1 \mathrm{~g} \mathrm{~kg}^{-1}$, Silte $=239,8 \mathrm{~g} \mathrm{~kg}^{-1}$ e Areia $=665,1 \mathrm{~g} \mathrm{~kg}^{-1}$ (EMBRAPA, 1997).
Utilizaram-se três cultivares de sorgo (Sorghum bicolor (L) Moech), selecionadas pelas características específicas de uso como forragem na região Nordeste, sendo: IPA 4-67/42, IPA 2-3-1 e IPA SF-25. Todas as variedades de sorgo forrageiro eram de porte médio a alto, com colmo suculento, executando-se a variedade IPA SF-25.

O preparo do solo foi realizado com uma aração (até 30 $\mathrm{cm}$ de profundidade) sem gradagem. Utilizaram-se quatro sementes a cada 0,20 m de sulco, sendo realizado o desbaste aos 10 dias, após a emergência; observando-se uma densidade de plantio de 15 plantas/metro linear. Ao longo do cultivo foram realizadas duas capinas. A manutenção da umidade do solo foi realizada através das precipitações pluviais e da irrigação complementar, quando necessário, computando-se o total acumulado.

A adubação precedente à semeadura foi realizada a lanço, aplicando-se $500 \mathrm{~kg} \mathrm{ha}^{-1}$ de esterco bovino. A cobertura de fósforo, na forma de superfosfato triplo $\left(\mathrm{P}_{2} \mathrm{O}_{5}\right)$, foi aplicada 20 dias após a emergência das plântulas e variou de acordo com os níveis estudados $\left(0 ; 40 ; 60 ; 90\right.$ e $\left.120 \mathrm{~kg} \mathrm{ha}^{-1}\right)$ na linha de cultivo a $15 \mathrm{~cm}$ do colo da planta.

As variáveis avaliadas foram: altura de plantas (m); fitomassa fresca de parte aérea e raiz $(\mathrm{g})$; fitomassa seca de parte aérea e raiz $(\mathrm{g})$; estande $\left(\mathrm{n}^{\mathrm{o}}\right.$ plantas $\left.\mathrm{ha}^{-1}\right)$; produção de forragem $\left(\mathrm{g} \mathrm{parcela}^{-1}\right)$; e rendimento de forragem $\left(\mathrm{kg} \mathrm{ha}^{-1}\right)$.

O delineamento estatístico utilizado foi o de blocos casualizados em esquema fatorial $(5 \times 3)$, com quatro repetições. Constituíram as parcelas os níveis de adubação fosfatada e as subparcelas, as variedades estudadas. A parcela experimental foi constituída por cinco fileiras de 4,0 m de comprimento, com espaçamento entre as linhas de $0,80 \mathrm{~m} \mathrm{e}$ 0,20 m entre plantas. Para efeito de coleta de dados, foram consideradas as três linhas centrais, eliminando-se $0,5 \mathrm{~m}$ nas extremidades das fileiras, sendo a área útil de 7,2 $\mathrm{m}^{2}$.

Os resultados obtidos foram submetidos à análise de variância pelo teste $\mathrm{F}$, a $5 \%$ de probabilidade. A comparação das médias foi realizada pelo teste de Tukey a $5 \%$ de probabilidade. Realizou-se a análise de regressão nos casos de efeito significativo das doses de P. A escolha do modelo selecionado para cada variável baseou-se na significância dos parâmetros e nos valores do R² (ALVAREZ; ALVAREZ, 2006). Utilizaram-se para análise dos dados os programas estatísticos SAEG e SISVAR (FERREIRA, 2003).

\section{Resultados e Discussão}

Os dados de altura de plantas, em função dos dias após o plantio (DAP), foram ajustados a um modelo de crescimento exponencial com tendência ao máximo $\left(\mathrm{R}^{2}=0,996, \mathrm{P}<0,01\right)$ (Figura 1), que evidenciou claramente um aumento na altura de plantas a partir de 28 DAP e tendência à estabilização em torno dos 100 DAP. A estabilização pode ser explicada pela maturidade fisiológica da planta e pela perda de água nos tecidos ao final do ciclo, o que determina o ponto de colheita.

A análise de regressão indicou que a altura de plantas, em função dos dias após o plantio (DAP) ajustou-se à equação (Figura 2), comprovando aumento da altura de 


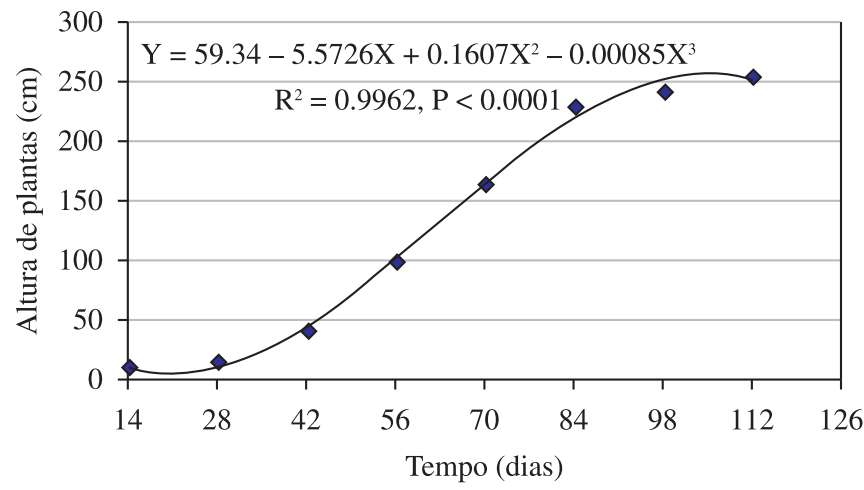

Figura 1. Análise de regressão para altura de plantas em função dos dias após o plantio (DAP) na cultura do sorgo forrageiro, Serra Talhada - PE, 2007.

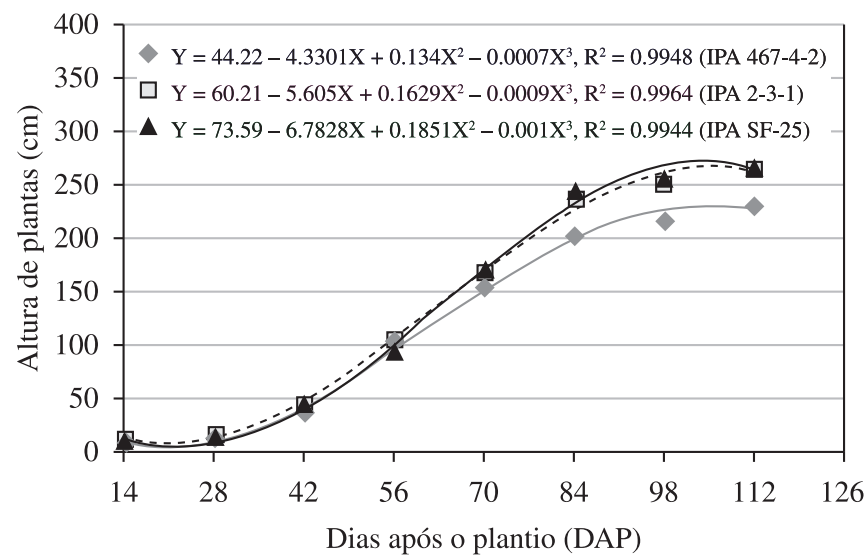

Figura 2. Análise de regressão para altura de plantas em função dos dias após o plantio (DAP) na cultura do sorgo forrageiro, variedades IPA 4-6-7/42, IPA 2-3-1 e IPA SF-25. Serra Talhada-PE, 2007.

plantas exponencialmente em relação ao período de avaliação, através do coeficiente de determinação que demonstra que $99,44 \%, 99,48 \%$ e $99,64 \%$ desse efeito pode ser explicado pela equação de primeiro grau, para as variedades IPA SF-25, IPA 4-6-7/42 e IPA 2-3-1, respectivamente. Observa-se ainda que o coeficiente de determinação foi significativo $(\mathrm{P}<0,01)$ no tempo para a variável altura de plantas, obtendo-se um valor máximo de $357,1 \mathrm{~cm}$ e menor de $184,4 \mathrm{~mm}$, respectivamente, o que corresponde aos valores de altura no período final do crescimento das plantas.

Na Figura 3, pode-se observar efeito linearmente significativo $(\mathrm{P}<0,05)$ para a variável altura de plantas, em função dos níveis de adubação com fósforo, em que os tratamentos com doses maiores de $\mathrm{P}_{2} \mathrm{O}_{5}$ resultaram em plantas com maior altura.

Na Tabela 1, encontram-se os valores $\left(\mathrm{g}\right.$ parcela $\left.{ }^{-1}\right)$ para fitomassa fresca de colmos de sorgo forrageiro, em função dos níveis de $\mathrm{P}_{2} \mathrm{O}_{5}$ aplicados. Observa-se que houve diferença estatística significativa $(\mathrm{P}<0,05)$ pelo teste de Tukey, tanto para os níveis de adubação fosfatada como para as variedades pesquisadas, destacando-se a IPA 4-6-7/42 das outras duas. Houve um ganho de $27,34 \%$ na massa verde de colmos quando a quantidade de $\mathrm{P}_{2} \mathrm{O}_{5}$ aplicada foi $120 \mathrm{~kg} \mathrm{ha}^{-1}$, em comparação com o tratamento sem adubação, o que pode também ser explicado pela maior altura de plantas

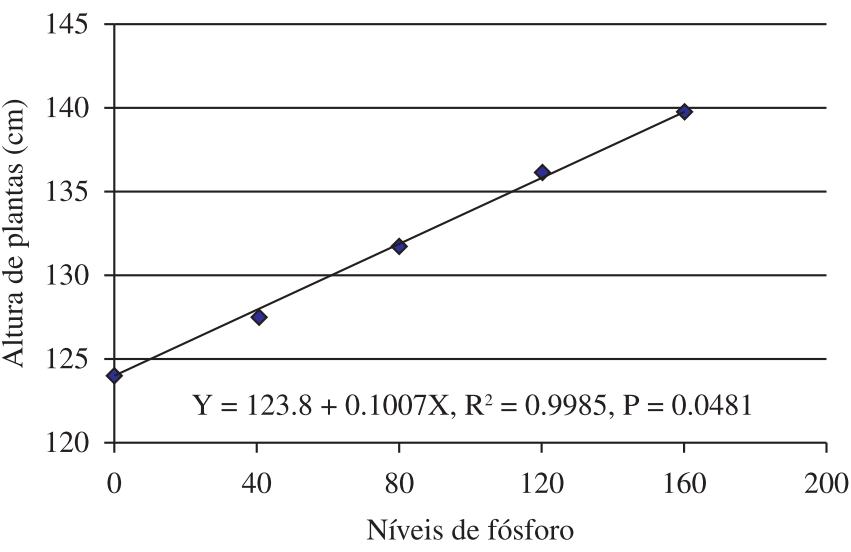

Figura 3. Análise de regressão para altura de plantas $(\mathrm{cm})$ de sorgo forrageiro em função dos níveis de adubação com $\mathrm{P}_{2} \mathrm{O}_{5}\left(\mathrm{~kg} \mathrm{ha}^{-1}\right)$. Serra Talhada - PE, 2007.

Tabela 1. Fitomassa fresca de colmos de três variedades de sorgo forrageiro (g parcela ${ }^{-1}$ ), em função dos níveis de adubação fosfatada no semiárido pernambucano, Serra Talhada, 2007.

\begin{tabular}{|c|c|c|c|c|}
\hline \multirow{3}{*}{$\begin{array}{c}\text { Níveis de } \\
\mathrm{P}_{2} \mathrm{O}_{5} \\
\left(\mathrm{~kg} \mathrm{ha}^{-1}\right)\end{array}$} & \multirow{2}{*}{\multicolumn{3}{|c|}{$\begin{array}{c}\text { Fitomassa Fresca de Colmos }\left(\mathrm{g} \mathrm{parcela}^{-1}\right) \\
\text { Variedades de Sorgo Forrageiro } \\
\end{array}$}} & \multirow{3}{*}{ Média } \\
\hline & & & & \\
\hline & IPA 4-6-7/42 & IPA 2-3-1 & IPA SF-25 & \\
\hline 0 & $3.600,0 \mathrm{~A}$ & $2.450,0 \mathrm{~B}$ & $2.325,0 \mathrm{~B}$ & $2.791,70 \mathrm{~b}$ \\
\hline 40 & $4.675,0 \mathrm{~A}$ & $3.625,0 \mathrm{~B}$ & $3.000,0 \mathrm{~B}$ & $3.766,70 \mathrm{ab}$ \\
\hline 80 & $4.550,0 \mathrm{~A}$ & $2.975,0 \mathrm{~B}$ & $3.900,0 \mathrm{~B}$ & $3.808,30 \mathrm{ab}$ \\
\hline 120 & $5.000,0 \mathrm{~A}$ & $3.275,0 \mathrm{~B}$ & $3.250,0 \mathrm{~B}$ & $3.841,70 \mathrm{a}$ \\
\hline 160 & $3.550,0 \mathrm{~A}$ & $2.250,0 \mathrm{~B}$ & $3.350,0 \mathrm{~B}$ & $3.050,00 \mathrm{ab}$ \\
\hline
\end{tabular}

Coeficiente de Variação (C.V.) VAR. $=19,68 \%$

Coeficiente de Variação (C.V.) ADUB. $=35,52 \%$

Médias seguidas das mesmas letras, minúsculas na coluna e maiúsculas na linha, não diferem estatisticamente entre si pelo teste de Tukey, a $5 \%$ de probabilidade.

linearmente correlacionada com os níveis de fósforo. Conforme Avelino et al. (2011), os sorgos utilizados para produção de silagem, geralmente de dupla aptidão, são selecionados de acordo com sua produção de massa verde por hectare e pela proporção de grãos que apresentam em sua constituição.

Os valores referentes à fitomassa fresca de panículas (g parcela ${ }^{-1}$ ) de sorgo forrageiro, em função dos níveis de adubação fosfatada, encontram-se demonstrados na Tabela 2. Verifica-se que houve diferença estatística significativa para as variedades pesquisadas, novamente com destaque para IPA 4-6-7/42, havendo, também, significância entre os níveis de adubação fosfatada, pelo teste de Tukey $(\mathrm{P}<0,05)$. Os resultados tendem a se correlacionar com os valores obtidos com os colmos.

São apresentados, na Tabela 3, os dados de fitomassa fresca de raízes de sorgo forrageiro em função dos níveis de adubação com fósforo. Observa-se que não houve diferença estatística significativa $(P>0,05)$ para as variedades e níveis de adubação analisadas, variando de 883 a $1.175 \mathrm{~g} \mathrm{parcela}^{-1}$, o que pode se explicado pela maior translocação de nutrientes para a parte aérea da planta e também pelo elevado coeficiente de 
Tabela 2. Fitomassa fresca de panículas de três variedades de sorgo forrageiro ( $\left(\right.$ parcela ${ }^{-1}$ ), em função dos níveis de adubação fosfatada no semiárido pernambucano, Serra Talhada, 2007.

\begin{tabular}{ccccc}
\hline \multirow{2}{*}{$\begin{array}{c}\text { Níveis de } \\
\mathbf{P}_{2} \mathbf{O}_{\mathbf{5}}\end{array}$} & \multicolumn{2}{c}{ Fitomassa Fresca de Panículas $\left(\mathbf{g ~ p a r c e l a}^{-1}\right)$} & \multirow{2}{*}{ Variedades de Sorgo Forrageiro } & \multirow{2}{*}{ Média } \\
\cline { 2 - 4 }$\left(\mathbf{k g ~ h a}^{-1}\right)$ & IPA 4-6-7/42 & IPA 2-3-1 & IPA SF-25 & \\
\hline 0 & $625,0 \mathrm{~A}$ & $375,0 \mathrm{~A}$ & $550,0 \mathrm{~A}$ & $516,70 \mathrm{~b}$ \\
40 & $525,0 \mathrm{~A}$ & $600,0 \mathrm{~A}$ & $625,0 \mathrm{~A}$ & $583,30 \mathrm{ab}$ \\
80 & $775,0 \mathrm{~A}$ & $725,0 \mathrm{~A}$ & $575,0 \mathrm{~A}$ & $691,70 \mathrm{a}$ \\
120 & $925,0 \mathrm{~A}$ & $475,0 \mathrm{~B}$ & $500,0 \mathrm{~B}$ & $633,30 \mathrm{ab}$ \\
160 & $875,0 \mathrm{~A}$ & $425,0 \mathrm{~B}$ & $450,0 \mathrm{~B}$ & $583,30 \mathrm{ab}$
\end{tabular}

Coeficiente de Variação (C.V.) VAR. $=13,51 \%$

Coeficiente de Variação (C.V.) ADUB. = 33,79\%

Médias seguidas das mesmas letras, minúsculas na coluna e maiúsculas na linha, não diferem estatisticamente entre si pelo teste de Tukey, a 5\% de probabilidade.

Tabela 3. Fitomassa fresca de raízes de três variedades de sorgo forrageiro (g parcela $\left.{ }^{-1}\right)$, em função dos níveis de adubação fosfatada no semiárido pernambucano, Serra Talhada, 2007.

\begin{tabular}{ccccc}
\hline \multirow{2}{*}{$\begin{array}{c}\text { Níveis de } \\
\mathbf{P}_{2} \mathbf{O}_{5}\end{array}$} & \multicolumn{2}{c}{ Fitomassa Fresca de Raízes $\left(\mathbf{g ~ p a r c e l a}^{-1}\right)$} & \multirow{2}{*}{ Védia } \\
\cline { 2 - 4 }$\left(\mathbf{k g ~ h a}^{-1}\right)$ & IPA 4-6-7/42 & IPA 2-3-1 & IPA SF-25 & \\
\hline 0 & $1.050,00 \mathrm{~A}$ & $875,00 \mathrm{~A}$ & $725,00 \mathrm{~A}$ & $883,33 \mathrm{a}$ \\
\hline 40 & $850,00 \mathrm{~A}$ & $1.000,00 \mathrm{~A}$ & $975,00 \mathrm{~A}$ & $941,68 \mathrm{a}$ \\
80 & $875,00 \mathrm{~A}$ & $1.300,00 \mathrm{~A}$ & $925,00 \mathrm{~A}$ & $1.033,33 \mathrm{a}$ \\
120 & $1.225,00 \mathrm{~A}$ & $1.275,00 \mathrm{~A}$ & $1.025,00 \mathrm{~A}$ & $1.175,00 \mathrm{a}$ \\
160 & $1.150,00 \mathrm{~A}$ & $975,00 \mathrm{~A}$ & $875,00 \mathrm{~A}$ & $1.000,00 \mathrm{a}$ \\
\hline
\end{tabular}

Médias seguidas das mesmas letras, minúsculas na coluna e maiúsculas na linha, não diferem estatisticamente entre si pelo teste de Tukey, a 5\% de probabilidade.

variação encontrado, 42,29\% e 47,37\%, respectivamente para variedade e adubação. A casualização em blocos possibilitou que eventuais distinções de relevo, água e nutrientes na área experimental fossem minimizadas com o delineamento adotado.

Na Tabela 4, encontram-se os valores de Fitomassa seca de colmos de três variedades de sorgo forrageiro, em função dos níveis de adubação com fósforo. As diferenças quantitativas apresentadas (875 a $1.625 \mathrm{~g} \mathrm{parcela}^{-1}$ ) não resultaram em diferenças estatísticas pelo teste de Tukey $(\mathrm{P}>0,05)$. É comum a avaliação da massa seca total da parte aérea, a partir do somatório dos valores de fitomassa seca de partes da planta (colmo, folhas e panículas); sendo esta a de maior importância, uma vez que será utilizada na alimentação animal.

$\mathrm{Na}$ Tabela 5, encontram-se os valores de Fitomassa seca de panículas de três variedades de sorgo forrageiro, em função dos níveis de adubação com fósforo. Houve diferença significativa para a variedade, tendo-se mostrado superior, quanto à produção de panículas para os níveis mais altos de $\mathrm{P}_{2} \mathrm{O}_{5}$, a variedade IPA 4-6-7/42. A maior exposição à luz proporciona
Tabela 4. Fitomassa seca de colmos de três variedades de sorgo forrageiro (g parcela ${ }^{-1}$ ), em função dos níveis de adubação fosfatada no semiárido pernambucano, Serra Talhada, 2007.

\begin{tabular}{ccccc}
\hline \multirow{2}{*}{$\begin{array}{c}\text { Níveis de } \\
\mathbf{P}_{2} \mathbf{O}_{\mathbf{5}}\end{array}$} & \multicolumn{2}{c}{ Fitomassa Seca de Colmos $\left(\mathbf{g ~ p a r c e l a}^{-1}\right)$} & \multirow{2}{*}{ Média } \\
\cline { 2 - 4 }$\left(\mathbf{k g ~ h a}^{-1}\right)$ & IPA 4-6-7/42 & IPA 2-3-1 & IPA SF-25 & \\
\hline 0 & $1.150,00 \mathrm{~A}$ & $1.000,00 \mathrm{~A}$ & $1.000,00 \mathrm{~A}$ & $1.050,00 \mathrm{a}$ \\
40 & $1.570,00 \mathrm{~A}$ & $1.275,00 \mathrm{~A}$ & $1.125,00 \mathrm{~A}$ & $1.325,00 \mathrm{a}$ \\
80 & $1.450,00 \mathrm{~A}$ & $1.250,00 \mathrm{~A}$ & $1.625,00 \mathrm{~A}$ & $1.441,70 \mathrm{a}$ \\
120 & $1.600,00 \mathrm{~A}$ & $1.475,00 \mathrm{~A}$ & $1.300,00 \mathrm{~A}$ & $1.458,30 \mathrm{a}$ \\
160 & $1.075,00 \mathrm{~A}$ & $875,00 \mathrm{~A}$ & $1.350,00 \mathrm{~A}$ & $1.100,00 \mathrm{a}$
\end{tabular}

Coeficiente de Variação (C.V.) VAR. = 39,91\%

Coeficiente de Variação (C.V.) ADUB. $=33,49 \%$

Médias seguidas das mesmas letras, minúsculas na coluna e maiúsculas na linha, não diferem estatisticamente entre si pelo teste de Tukey, a 5\% de probabilidade.

Tabela 5. Fitomassa seca de panícula de três variedades de sorgo forrageiro (g parcela $\left.{ }^{-1}\right)$, em função dos níveis de adubação fosfatada no semiárido pernambucano, Serra Talhada, 2007.

\begin{tabular}{|c|c|c|c|c|}
\hline \multirow{3}{*}{$\begin{array}{c}\text { Níveis de } \\
\mathbf{P}_{2} \mathrm{O}_{5} \\
\left(\mathrm{~kg} \mathrm{ha}^{-1}\right)\end{array}$} & \multicolumn{3}{|c|}{ Fitomassa Seca de Panículas (g parcela ${ }^{-1}$ ) } & \multirow{3}{*}{ Média } \\
\hline & \multicolumn{3}{|c|}{ Variedades de Sorgo Forrageiro } & \\
\hline & IPA 4-6-7/42 & IPA 2-3-1 & IPA SF-25 & \\
\hline 0 & $425,00 \mathrm{~A}$ & $200,00 \mathrm{~A}$ & $300,00 \mathrm{~A}$ & $308,30 \mathrm{a}$ \\
\hline 40 & $300,00 \mathrm{~A}$ & $375,00 \mathrm{~A}$ & $450,00 \mathrm{~A}$ & $375,00 \mathrm{a}$ \\
\hline 80 & $500,00 \mathrm{~A}$ & $500,00 \mathrm{~A}$ & $350,00 \mathrm{~A}$ & $450,00 \mathrm{a}$ \\
\hline 120 & $600,00 \mathrm{~A}$ & $325,00 \mathrm{~B}$ & $275,00 \mathrm{~B}$ & $400,00 \mathrm{a}$ \\
\hline 160 & $650,00 \mathrm{~A}$ & $250,00 \mathrm{~B}$ & $325,00 \mathrm{~B}$ & $408,30 \mathrm{a}$ \\
\hline \multicolumn{5}{|c|}{$\begin{array}{l}\text { Coeficiente de Variação (C.V.) VAR. = 37,86\% } \\
\text { Coeficiente de Variação (C.V.) ADUB = 36,69\% }\end{array}$} \\
\hline
\end{tabular}

Médias seguidas das mesmas letras, minúsculas na coluna e maiúsculas na linha, não diferem estatisticamente entre si pelo teste de Tukey, a 5\% de probabilidade.

uma taxa fotossintética maior, o que, provavelmente, ocasiona um acúmulo de carboidratos transformados em massa seca em toda a parte aérea da planta (TERRA et al., 2010).

São apresentados, na Tabela 6, os dados de fitomassa seca de raízes de sorgo forrageiro em função dos níveis de adubação com fósforo. Observa-se que não houve diferença estatística significativa $(\mathrm{P}>0,05)$ para as variedades e níveis de adubação analisadas, variando de 475,0 a 558,3 $\mathrm{g}_{\text {parcela }}{ }^{-1}$. De acordo com Magalhães, Durães e Rodrigues (2000), as raízes do sorgo têm seu crescimento diretamente relacionado com a temperatura do ar, sendo limitado pela falta de umidade no solo e disponibilidade de fotoassimilados oriundos das folhas, terminando antes do florescimento, quando a planta prioriza a nutrição das panículas.

Na Tabela 7, encontram-se os valores referentes ao número de plantas de três variedades de sorgo forrageiro, em função dos níveis de adubação com fósforo. Dos dados, observa-se que não houve diferença estatística significativa $(\mathrm{P}>0,05)$ entre as variedades e os níveis de adubação com fósforo. $\mathrm{O}$ número de plantas por metro linear está diretamente associado 
Tabela 6. Fitomassa seca de raízes de três variedades de sorgo forrageiro (g parcela ${ }^{-1}$ ), em função dos níveis de adubação fosfatada no semiárido pernambucano. Serra Talhada, 2007.

\begin{tabular}{|c|c|c|c|c|}
\hline \multirow{3}{*}{$\begin{array}{c}\text { Níveis de } \\
\mathbf{P}_{2} \mathbf{O}_{5} \\
\left(\mathrm{~kg} \mathrm{ha}^{-1}\right)\end{array}$} & \multicolumn{3}{|c|}{ Fitomassa Seca de Raízes (g parcela-1) } & \multirow{3}{*}{ Média } \\
\hline & \multicolumn{3}{|c|}{ Variedades de Sorgo Forrageiro } & \\
\hline & IPA 4-6-7/42 & IPA 2-3-1 & IPA SF-25 & \\
\hline 0 & $625,00 \mathrm{~A}$ & $450,00 \mathrm{~A}$ & $350,00 \mathrm{~A}$ & $475,00 \mathrm{a}$ \\
\hline 40 & $475,00 \mathrm{~A}$ & $525,00 \mathrm{~A}$ & $550,00 \mathrm{~A}$ & $516,70 \mathrm{a}$ \\
\hline 80 & $550,00 \mathrm{~A}$ & $750,00 \mathrm{~A}$ & $525,00 \mathrm{~A}$ & $608,30 \mathrm{a}$ \\
\hline 120 & $625,00 \mathrm{~A}$ & $800,00 \mathrm{~A}$ & $550,00 \mathrm{~A}$ & $658,30 \mathrm{a}$ \\
\hline 160 & $750,00 \mathrm{~A}$ & $625,00 \mathrm{~A}$ & $450,00 \mathrm{~A}$ & $608,30 \mathrm{a}$ \\
\hline \multicolumn{5}{|c|}{$\begin{array}{l}\text { Coeficiente de Variação (C.V.) VAR. }=56,23 \% \\
\text { Coeficiente de Variação (C.V.) ADUB = 59,49\% }\end{array}$} \\
\hline
\end{tabular}

Médias seguidas das mesmas letras, minúsculas na coluna e maiúsculas na linha, não diferem estatisticamente entre si pelo teste de Tukey, a 5\% de probabilidade.

Tabela 7. Número de plantas de três variedades de sorgo forrageiro (plantas $\mathrm{ha}^{-1}$ ), em função dos níveis de adubação fosfatada no semiárido pernambucano. Serra Talhada, 2007.

\begin{tabular}{ccccc}
\hline \multirow{2}{*}{$\begin{array}{c}\text { Níveis de } \\
\mathbf{P}_{2} \mathbf{O}_{5} \\
\left(\text { kg ha }^{-1}\right)\end{array}$} & \multicolumn{3}{c}{ Número de Plantas (plantas ha $\left.{ }^{-1}\right)$} & \multirow{2}{*}{ Média } \\
\cline { 2 - 4 } & IPA 4-6-7/42 & IPA 2-3-1 & IPA SF-25 & \\
\hline 0 & $178.846 \mathrm{AB}$ & $179.167 \mathrm{~A}$ & $172.917 \mathrm{~B}$ & $176.910 \mathrm{a}$ \\
40 & $186.458 \mathrm{~A}$ & $170.312 \mathrm{~B}$ & $182.812 \mathrm{AB}$ & $179.861 \mathrm{a}$ \\
80 & $183.333 \mathrm{~A}$ & $175.521 \mathrm{~B}$ & $184.894 \mathrm{~A}$ & $181.250 \mathrm{a}$ \\
120 & $187.500 \mathrm{~A}$ & $179.687 \mathrm{~B}$ & $181.250 \mathrm{AB}$ & $182.812 \mathrm{a}$ \\
160 & $183.854 \mathrm{~A}$ & $179.167 \mathrm{~B}$ & $176.562 \mathrm{~B}$ & $179.861 \mathrm{a}$ \\
\hline & & & \\
\hline
\end{tabular}

Médias seguidas das mesmas letras, minúsculas na coluna e maiúsculas na linha, não diferem estatisticamente entre si pelo teste de Tukey, a 5\% de probabilidade.

à produtividade da cultura e às condições de umidade do solo na fase vegetativa, bem como ao espaçamento empregado entre fileiras. A quantidade de adubo fornecida à cultura, embora estatisticamente não significativa, incrementou o número de plantas, variando de 172.917 a 187.500 plantas por hectare.

São apresentados, na Tabela 8 , a produção total de forragem da parte aérea da planta (colmo + panícula), de sorgo forrageiro, em função dos níveis de adubação fosfatada. Observa-se que houve diferença estatística significativa $(\mathrm{P}<0,05)$ pelo teste de Tukey, tanto para os níveis de adubação fosfatada como para as variedades pesquisadas, destacando-se a IPA 4-6-7/42 das demais variedades estudadas. $\mathrm{O}$ alto potencial de produção por área e o alto conteúdo de carboidratos não fibrosos, aliados à sua maior tolerância a déficits hídricos, tornam a planta do sorgo uma excelente opção forrageira para alimentação animal (MELO; NÖRNBERG; ROCHA, 2004).

Na Tabela 9, encontra-se o rendimento de forragem (colmo + panícula + raiz), em quilogramas por hectare, de três variedades de sorgo forrageiro, em função dos níveis de adubação fosfatada no semiárido pernambucano. Verifica-se que
Tabela 8. Produção de forragem (colmo + panícula), em g parcela ${ }^{-1}$, de três variedades de sorgo forrageiro, em função dos níveis de adubação fosfatada no semiárido pernambucano, Serra Talhada, 2007.

\begin{tabular}{ccccc}
\hline \multirow{2}{*}{$\begin{array}{c}\text { Níveis de } \\
\mathbf{P}_{2} \mathbf{O}_{\mathbf{5}}\end{array}$} & \multicolumn{2}{c}{ Produção de Forragem $\left(\mathbf{g ~ p a r c e l a ~}^{-1}\right)$} & \multirow{2}{*}{ Variedades de Sorgo Forrageiro } & \multirow{2}{*}{ Média } \\
\cline { 2 - 4 }$\left(\mathbf{k g ~ h a}^{-1}\right)$ & IPA 4-6-7/42 & IPA 2-3-1 & IPA SF-25 & \\
\hline 0 & $4.225,00 \mathrm{~A}$ & $2.825,00 \mathrm{~A}$ & $2.875,00 \mathrm{~A}$ & $3.308,33 \mathrm{~b}$ \\
40 & $5.200,00 \mathrm{~A}$ & $4.225,00 \mathrm{~A}$ & $3.625,00 \mathrm{~A}$ & $4.350,00 \mathrm{ab}$ \\
80 & $5.325,00 \mathrm{~A}$ & $3.700,00 \mathrm{~A}$ & $4.475,00 \mathrm{~A}$ & $4.500,00 \mathrm{a}$ \\
120 & $5.925,00 \mathrm{~A}$ & $3.750,00 \mathrm{~B}$ & $3.750,00 \mathrm{~B}$ & $4.475,00 \mathrm{a}$ \\
160 & $4.425,00 \mathrm{~A}$ & $2.675,00 \mathrm{~A}$ & $3.800,00 \mathrm{~A}$ & $3.633,33 \mathrm{ab}$
\end{tabular}

Coeficiente de Variação (C.V.) VAR. $=17,66 \%$

Coeficiente de Variação (C.V.) ADUB. $=32,14 \%$

Médias seguidas das mesmas letras, minúsculas na coluna e maiúsculas na linha, não diferem estatisticamente entre si pelo teste de Tukey, a 5\% de probabilidade.

Tabela 9. Rendimento de forragem (colmo + panícula + raiz), em kg ha ${ }^{-1}$, de três variedades de sorgo forrageiro, em função dos níveis de adubação fosfatada no semiárido pernambucano, Serra Talhada, 2007.

\begin{tabular}{|c|c|c|c|c|}
\hline \multirow{3}{*}{$\begin{array}{c}\text { Níveis de } \\
\mathbf{P}_{2} \mathrm{O}_{5} \\
\left(\mathrm{~kg} \mathrm{ha}^{-1}\right)\end{array}$} & \multicolumn{3}{|c|}{ Rendimento de Forragem $\left(\mathrm{kg} \mathrm{ha}^{-1}\right)$} & \multirow{3}{*}{ Média } \\
\hline & \multicolumn{3}{|c|}{ Variedades de Sorgo Forrageiro } & \\
\hline & IPA 4-6-7/42 & IPA 2-3-1 & IPA SF-25 & \\
\hline 0 & $5.868,05 \mathrm{~A}$ & $3.923,61 \mathrm{~A}$ & $3.993,05 \mathrm{~A}$ & $4.594,91 \mathrm{~b}$ \\
\hline 40 & $7.222,22 \mathrm{~A}$ & $5.868,05 \mathrm{~A}$ & $5.034,72 \mathrm{~A}$ & $6.041,67 \mathrm{ab}$ \\
\hline 80 & $7.395,83 \mathrm{~A}$ & $5.138,89 \mathrm{~A}$ & $6.215,27 \mathrm{~A}$ & $6.249,99 \mathrm{a}$ \\
\hline 120 & $8.229,17 \mathrm{~A}$ & $5.208,33 \mathrm{~B}$ & $5.208,33 \mathrm{~B}$ & $6.215,28 \mathrm{a}$ \\
\hline 160 & $6.145,83 \mathrm{~A}$ & $3.715,28 \mathrm{~A}$ & $5.277,78 \mathrm{~A}$ & $5.046,30 \mathrm{ab}$ \\
\hline \multicolumn{5}{|c|}{ Coeficiente de Variação (C.V.) VAR. = 17,66\% } \\
\hline
\end{tabular}

Médias seguidas das mesmas letras, minúsculas na coluna e maiúsculas na linha, não diferem estatisticamente entre si pelo teste de Tukey, a 5\% de probabilidade.

houve diferença estatística significativa $(\mathrm{P}<0,05)$ pelo teste de Tukey, tanto para os níveis de adubação com $\mathrm{P}_{2} \mathrm{O}_{5}$ como para as variedades pesquisadas, com destaque para IPA 4-6-7/42 que obteve um rendimento de até $8.229,17 \mathrm{~kg} \mathrm{ha}^{-1}$, quando recebeu adubação fosfatada na proporção de $120 \mathrm{~kg} \mathrm{ha}^{-1}$, em contraste com a variedade SF-25, que rendeu apenas 3.993,05 $\mathrm{kg} \mathrm{ha}^{-1}$, na ausência de qualquer adubação. Através dos dados apresentados, evidencia-se que a adubação com $\mathrm{P}_{2} \mathrm{O}_{5}$, na dose de $120 \mathrm{~kg} \mathrm{ha}^{-1}$, possibilitou a máxima eficiência econômica no rendimento total de forragem, justificando, assim, a aplicação de adubos fosfatados na cultura do sorgo.

\section{Conclusões}

Os efeitos das doses de fósforo $\left(\mathrm{P}_{2} \mathrm{O}_{5}\right)$ foram independentes dos efeitos das variedades estudadas.

A variedade IPA 4-6-7/42 apresentou melhor desempenho em relação às outras duas variedades em todos os parâmetros analisados. 
A adubação com $\mathrm{P}_{2} \mathrm{O}_{5}$ na dose de $120 \mathrm{~kg} \mathrm{ha}^{-1}$ possibilitou a máxima eficiência econômica no rendimento total de forragem.

\section{Referências}

ALVAREZ V., V. H.; ALVAREZ, G. A. M. Comparações de médias ou testes de hipóteses? Contrastes! Boletim Informativo da Sociedade Brasileira de Ciencia do Solo, Campinas, v. 31, p. 24-34, 2006.

AVELINO, P. M. et al. Características agronômicas e estruturais de híbridos de sorgo em função de diferentes densidades de plantio. Revista Ciência Agronômica, Fortaleza, v. 42, n. 2, p. 534541, 2011. http://dx.doi.org/10.1590/S1806-66902011000200037

EMBRAPA. Centro Nacional de Pesquisa de Solos. Manual de métodos de análise de solo. 2. ed. rev. atual. Rio de Janeiro, 1997. 212 p. (EMBRAPA-CNPS, Documentos, n. 1).

EMBRAPA. Centro Nacional de Pesquisa de Solos. Sistema brasileiro de classificação de solos. Brasília: EMBRAPA, 1999. 412 p.

FERREIRA, D. F. Sisvar versão 4.3. Universidade Federal de Lavras, 2003. Disponível em: <http://www.dex.ufla.br/danielff/ sisvar>. Acesso em: 10 jun. 2011.

GRANT, C. A. et al. A importância do Fósforo no desenvolvimento inicial da planta. Associação Brasileira para Pesquisa da Potassa e do Fósforo - POTAFOS, set. 2001. 16 p. (Informações Agronômicas, n. 95).
LIMA, G. S. Estudo comparativo da resistência à seca no sorgo forrageiro (Sorghum bicolor (L.) Moench) em diferentes estádios de desenvolvimento. 1998. 128 f. Dissertação (Mestrado em Botânica)-Universidade Federal Rural de Pernambuco, Recife, 1998

MAGALHÃES, P. C.; DURÃES, F. O. M.; RODRIGUES, J. A. S. Sistema radicular. In: RODRIGUES, J. A. S.; VERSIANI, R. P.; FERREIRA, M. T. R. Cultivo do sorgo. Sete Lagoas: Embrapa Milho e Sorgo, 2000. Disponível em: <http://sistemasdeproducao. cnptia.embrapa.br/FontesHTML/Sorgo/CultivodoSorgo/index. htm>. Acesso em: 16 jul. 2011.

MELO, R.; NÖRNBERG, J. L.; ROCHA, M. G. Potencial produtivo e qualitativo de híbridos de milho, sorgo e girassol para ensilagem. Revista Brasileira deAgrociência, Pelotas, v. 10, n. 1, p. 87-95, 2004.

OLIVEIRA, R.P. et al. Características agronômicas de cultivares de sorgo (Sorghum bicolor (L.) Moench) sob três doses de nitrogênio. Pesquisa Agropecuária Tropical, Goiania, v. 35, n. 1, p. 45-53, 2005.

TERRA, T. G. R. et al. Desenvolvimento e produtividade de sorgo em função de diferentes densidades de plantas. Bioscience Journal, Uberlandia, v. 26, n. 2, p. 208-215, 2010.

THOMAZINI, M. J.; PACHECO, E. P.; CAVALCANTE, M. J. B. Avaliação e introdução de cultivares de sorgo e milheto no Estado do Acre. Rio Branco: Embrapa Acre, 2004. 26 p. (Embrapa Acre. Boletim de Pesquisa e Desenvolvimento, n. 40).

OMETTO, J. C. Bioclimatologia Vegetal. São Paulo: Editora Agronômica Ceres Ltda, 1981. 448 p. 